\title{
Cytogenetic analysis of day-7 bovine embryos by cytophotometric DNA measurements
}

\author{
M. Dorland ${ }^{1}$, W. A. L. Duijndam ${ }^{2}$, Th. A. M. Kruip ${ }^{3}$ and \\ J. A. van der Donk ${ }^{1}$ \\ ${ }^{1}$ Department of Cell Biology and Histology, Faculty of Veterinary Medicine, University of Utrecht, \\ The Netherlands; ${ }^{2}$ Department of Cytochemistry and Cytometry, Sylvius Laboratories, Faculty of \\ Medicine, University of Leiden, The Netherlands; and ${ }^{3}$ Department of Herd Health and Reproduction, \\ Faculty of Veterinary Medicine, University of Utrecht, The Netherlands
}

\begin{abstract}
A Feulgen staining procedure that stains the DNA of individual fixed nuclei stoichiometrically was used to analyse cytophotometrically the incidence of total ploidy and mixoploidy in 28 day-7 bovine embryos that had been fixed after collection ('non-cultured' embryos). The influence of culture on the incidence of chromosome abnormalities was further studied in another group of 24 embryos ('cultured' embryos) by culturing them for $24 \mathrm{~h}$ in Whittingham's medium. Of the total 52 embryos studied, two appeared to be entirely abnormal: one embryo was completely haploid, whereas the other embryo was completely triploid. Individual hyperdiploid nuclei and hypodiploid nuclei were frequently observed in the otherwise diploid embryos. As haploid polar bodies can still be present in morulae and blastocysts (to a maximum of three), only embryos with more than three hypodiploid nulcei were considered as abnormal. Of the 'non-cultured' embryos, $33.3 \%$ had one or more hyperdiploid nuclei, whereas $51.9 \%$ had more than three hypodiploid nuclei. In this latter group, $35.7 \%$ of the embryos also had hyperdiploid nuclei. The results also showed that day-7 bovine embryos that are completely haploid, completely triploid or mixoploid cannot be detected only by examining their morphology. It is concluded that the incidence of, especially, mixoploidy in embryos can be better studied by measuring the DNA content of the individual nuclei of an embryo rather than by analysing chromosomes, as in the latter method only dividing cells can be analysed. The presence of hyperdiploid and hypodiploid nuclei may indicate the frequent occurrence of mitotic segregation failures during mitosis in bovine embryos. These segregation failures may cause the death of cells, which in turn may contribute to a reduced embryo viability. This contention is supported by the results of the 'cultured' embryos that show that in this group the mean percentage of hypodiploid nuclei was lower than that in the group of 'non-cultured' embryos, whereas the mean number of nuclei and the mean percentage of degenerated nuclei was approximately the same in both groups of 'non-cultured' and 'cultured' embryos.
\end{abstract}

\section{Introduction}

The usual rate of survival to term after transfer of a single bovine embryo is approximately 60\% (Greve and Del Campo, 1986). This is similar to the percentage that is observed after spontaneous ovulation and artificial insemination (Sreenan and Diskin, 1986). Most of the embryos that do not result in a pregnancy are lost during the first 3 weeks of gestation (Sreenan and Diskin, 1986; Kastelic et al., 1991). It is assumed that these losses occur predominantly between days 15 and 18 after oestrus (Sreenan and Diskin, 1986). One of the possible reasons for loss during the preimplantation phase is the presence of chromosome abnormalities in the embryo (reviewed by King, 1990). Of the chromosome abnormalities that have been

Revised manuscript received 30 April 1993. found in embryos, mixoploidy (for example diploidy-haploidy, diploidy-triploidy) is the most commonly observed (Kind, 1990). Mixoploidy has been found more often in embryos that were morphologically abnormal than in embryos that were morphologically normal (King et al., 1987, 1988) in cows. Gonadotrophins, which are used for superovulation, may increase (Long and Williams, 1980) or decrease (Murray et al., 1986b) the frequency of these aberrations. In addition, culturing the embryos may increase the number of polyploid cells (Barlow and Sherman, 1972; Johnson and Rossant, 1981).

The cytogenetic evaluation of embryos by chromosome analysis encounters two major problems. First, few cells are in mitosis, even when a metaphase blocker is used (King et al., 1979; Singh and Hare, 1980; Rottman, 1981; King and Linares, 1983; Murray et al., 1985; King et al., 1987). It is therefore not always possible to detect or identify the degree of mixoploidy. 
Second, the occurrence of hypodiploid cells has to be interpreted with caution, as chromosomes can be lost during slide preparation (Murray et al., 1985; King et al., 1988; King, 1990).

In the study reported here these two problems have been overcome by measuring quantitatively the DNA content of the individual interphase nuclei. A similar approach has been used for embryos of other species (mouse: Barlow and Sherman, 1972; Barlow et al., 1972; Rossant and Tamura-Lis, 1981; Molls et al., 1982; Bolton et al., 1984; Chrisholm, 1988; human: Angell et al., 1983; O'Rand et al., 1986; rabbit: Fischer and Schumacher, 1991). The various phases of the cell cycle (G1 phase, S phase and G2 phase) are characterized by differences in the DNA content of the cell nucleus. Cells in the G2 phase have the maximum DNA content, which is twice the DNA content of cells in the G1 phase. The DNA content of cells in the S phase is intermediate, as during this phase DNA is being synthesized. Haploid and hypodiploid GI nuclei will have a DNA content that is less than the DNA content of the diploid G1 nuclei, whereas hyperdiploid and polyploid G2 nuclei will have a DNA content that is more than the DNA content of the diploid G2 nuclei.

The aim of this study was to determine the incidence of aneuploidy in day-7 bovine embryos developed in vivo, as these embryos are commonly used for embryo transfer. A FeulgenSchiff staining procedure was used to stain the DNA in individual nuclei of the embryos. The dye pararosaniline that is used in this procedure binds stoichiometrically to the apurinic acid in hydrolysed DNA to produce a coloured complex (Duijndam and Van Duijn, 1975). The abundance of this coloured complex, which is a measure of the amount of DNA in the nuclei, was measured by using stage scanning cytophotometry. This type of cytometry is highly accurate. This is illustrated in a study by Van der Ploeg et al. (1977), who repeatedly measured (four times) Feulgen-stained nuclei of various types of cell. In this study, the nuclei of white blood cells and human fibroblasts had mean integrated absorbance values of the order of 7000 arbitrary units, whereas the coefficient of variance varied only between 0.3 to 2.4. Furthermore, the influence of (residual) cytophotometrical errors is relatively low and methods are available to correct for these errors (Duijndam et al., 1980a, b). Glare is almost negligible (Duijndam et al, 1980a, b; Mares and Van der Ploeg, 1980); the total correction factor for residual distributional and diffraction errors depends upon the size and the local absorbance of the nuclei, but is generally low in cytophotometrical practice. For example, in the study of Mares and Van der Ploeg (1980), this total correction factor was $1.5 \%$ and $6.5 \%$ for the nuclei of Purkinje cells and granule cells, respectively.

As day- 7 bovine embryos are usually stored for several hours in a phosphate-buffered medium prior to transfer, the influence of culture on the incidence of aneuploidy was also investigated. This was studied by comparing freshly collected embryos with embryos that had been cultured for $24 \mathrm{~h}$ in a frequently used storage buffer (Whittingham's medium; Whittingham, 1971).

\section{Materials and Methods}

\section{Superovulation}

Dutch Friesian cows were treated with 3000 i.u. pregnant mares' serum gonadotrophin (PMSG; Folligonan: Intervet B.V.,
Boxmeer) at day 10 of the oestrous cycle (Dieleman and Bevers, 1987). Luteolysis was induced $48 \mathrm{~h}$ after PMSG injection with $22.5 \mathrm{mg}$ prostaglandin (PG; Prosolvin: Intervet B.V.).

A rapid solid-phase radioimmunoassay method (Dieleman and Bevers, 1987) was used to estimate the LH surge in the donor cows. The cows were treated with anti-PMSG (Neutra PMSG: Intervet B.V.) at 6-12 h after the maximum of the $\mathrm{LH}$ surge and inseminated $10-12 \mathrm{~h}$ after the maximum of the $\mathrm{LH}$ surge.

\section{Embryo collection, qualification and culture}

Embryos were collected from dissected uteri of slaughtered cows at day 7 after insemination. The uteri were flushed via the oviduct with $50 \mathrm{ml}$ of Dulbecco's phosphate-buffered saline solution (PBS: Difco, Detroit, MI) per uterine horn.

Immediately after collection, embryos were placed in PBS supplemented with $0.33 \mathrm{mmol}$ sodium pyruvate $\mathrm{I}^{-1}, 5.56 \mathrm{mmol}$ glucose $1^{-1}, 3 \mathrm{~g} \mathrm{BSA} \mathrm{l}^{-1}$ (BSA: Fluka Chemie AG, Bucks), $10^{5}$ i.u. penicillin/streptomycin $l^{-1}$ and $100 \mathrm{ml}$ heat-inactivated fetal calf serum $1^{-1}$ (FCS: Gibco, Breda) (Whittingham, 1971) at $37^{\circ} \mathrm{C}$. Embryos were classified into four quality groups (excellent, good, fair and poor) according to the criteria of Lindner and Wright (1983), using a stereomicroscope (Wild, $\times 50$, equipped with a $37^{\circ} \mathrm{C}$ warm plate) and photographed through an inverted phase-contrast microscope (Olympus, CK2, $\times 200$ ). One group of embryos was fixed immediately after being photographed ('non-cultured' embryos). Another group of embryos was transferred to fresh Whittingham's medium, and cultured for $24 \mathrm{~h}$ at $37^{\circ} \mathrm{C}$ ('cultured' embryos). The latter embryos were photographed for a second time after this culture period.

\section{Preparation of microscope slides}

Preparations were made from entire embryos. 'Non-cultured' embryos were cooled to $4^{\circ} \mathrm{C}$, and placed in a hypotonic solution $\left(0.075 \mathrm{~mol} \mathrm{KCl} \mathrm{l}^{-1}\right)$ at $4^{\circ} \mathrm{C}$ for $\mathrm{I}$ h. They were further processed as described by Dyban (1983). This procedure includes overnight fixation in a mixture of glacial acetic acid and absolute methanol ( $1: 3, v: v)$ at $-20^{\circ} \mathrm{C}$, followed by treatment (at $20^{\circ} \mathrm{C}$ ) with a softening solution (a mixture of $75 \%$ acetic acid and absolute methanol, $1: 4, v: v)$ to spread the cells on the slide.

'Cultured' embryos were placed in a hypotonic solution $\left(0.075 \mathrm{~mol} \mathrm{KCl}^{-1}\right)$ at $37^{\circ} \mathrm{C}$ for $10-15 \mathrm{~min}$. They were further processed by the method described by King et al. (1979), which includes fixation and spreading of the embryo on a warm slide $\left(37^{\circ} \mathrm{C}\right)$ by adding a 1:1 (v:v) mixture of glacial acetic acid and absolute methanol at $4^{\circ} \mathrm{C}$. All preparations were fixed for a second time for $\mathrm{I} \mathrm{h}$ in a freshly prepared mixture of absolute methanol, formaldehyde (35\%) and glacial acetic acid (85:10:5, $\mathrm{v}: \mathrm{v})$, and were then washed in absolute methanol. After a final rinse in distilled water, the preparations were dried under a stream of $\mathrm{N}_{2}$. Both techniques resulted in preparations with mainly the interphase nuclei and metaphase plates left.

In this study, 52 embryos, which had been collected from 20 cows, were analysed. Of these embryos, 28 formed the group of 'non-cultured' embryos and 24 the group of 'cultured' embryos.

\section{Feulgen staining and stage scanning cytophotometry}

Preparations were hydrolysed in $5 \mathrm{~mol} \mathrm{HCl}^{-1}$ for $1 \mathrm{~h}$ at $20^{\circ} \mathrm{C}$, and stained in a pararosaniline- $\mathrm{SO}_{2}-$ Schiff solution, Downloaded from Bioscientifica.com at 04/26/2023 01:07:58PM 
prepared according to Graumann (1953), for $45 \mathrm{~min}$ at $20^{\circ} \mathrm{C}$. The preparations were rinsed by subsequent washings in sulfurous acid $(3 \times 10 \mathrm{~min}), 0.1 \mathrm{~mol}$ citric acid $\mathrm{l}^{-1} / 0.2 \mathrm{~mol} \mathrm{Na} \mathrm{HPO}_{4} \mathrm{l}^{-1}$

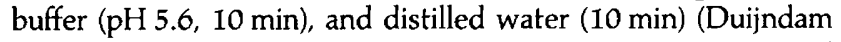
and Van Duijn, 1973). Dehydration was obtained with a graded ethanol-xylene series. Preparations were embedded in $\mathrm{DePeX}$ (Gurr, BDH, Poole).

The DNA content of the individual interphase nuclei was measured by absorbance scanning at $559 \mathrm{~nm}$ with a Cytoscan SMP (Zeiss, Oberkochen) interfaced to a PDP 11/10 computer with a HIDACSYS-ARRAYSCAN program (Van der Ploeg et al., 1977). Measurements were taken at intervals of $0.5 \mu \mathrm{m}$. For each nucleus, the integrated absorbance (obtained by summation of the local absorbance values after subtraction of the mean background value) was determined. The integrated absorbance values (DNA values) were calculated in arbitrary units. The correction factor for (residual) cytophotometric errors was determined by measuring 100 nuclei of a representative embryo. The nuclei of this embryo had a mean area of $1489 \pm 327$ measuring spots of $0.25 \mu \mathrm{m}^{2}$ and a mean local absorbance of $0.07 \pm 0.02$. According to Duijndam et al. $(1980 a, b)$, the correction factor for the combination of diffraction, glare and distributional errors in this case was $1 \%$ or less and this was considered as negligible.

Degenerated nuclei were also present in the preparations. These nuclei were either lysed or pycnotic. Only the DNA content of a part of the pycnotic nuclei was measured, as these nuclei still appeared intact.

Actively dividing calf kidney fibroblasts were used to obtain normal diploid DNA values. These cells were cultured in an enriched L-15 medium on cover glasses and were, although not treated with a hypotonic solution, fixed and postfixed with similar solutions to those used to fix the embryos.

\section{Identification of hyperdiploid and hypodiploid nuclei}

The minimum and the maximum of the normal G1 and G2 values in a particular embryo could not be calculated, as the number of nuclei per embryo was usually low in each phase of the cell cycle. Instead, for each embryo, these values were estimated from the frequency distribution of the measured DNA values. This estimation was based on the assumption that the G1 values are half of the G2 values and on the assumption that both the $G 1$ and the $G 2$ values are normally distributed, as has been shown for non-dividing G1-phase Purkinje cells (Mares and Van der Ploeg, 1980). The mode of the GI distribution was determined from the frequency distribution of DNA values. This mode was considered to be the $2 \mathrm{C}$ value, since in a normal distribution the median approximates the mode. Although the $4 \mathrm{C}$ value was not further used, it was calculated from this $2 \mathrm{C}$ value. The 'maximum G2 value' was also determined from the frequency distribution of DNA values. This value was defined by the nucleus with the highest integrated absorbance of less than $5 \mathrm{C}$, since nuclei that have a DNA value of $5 \mathrm{C}$ or more can be considered as hyperdiploid or polyploid (Fischer and Schumacher, 1991). This 5C limit was calculated from the observed $2 \mathrm{C}$ value. The 'maximum G1 value' was obtained by dividing the 'maximum G2 value' by 2 . The 'minimum G1 value' could be estimated from the 'maximum GI value' by using the $2 \mathrm{C}$ value (i.e. the mode) as a mirror. Nuclei with a

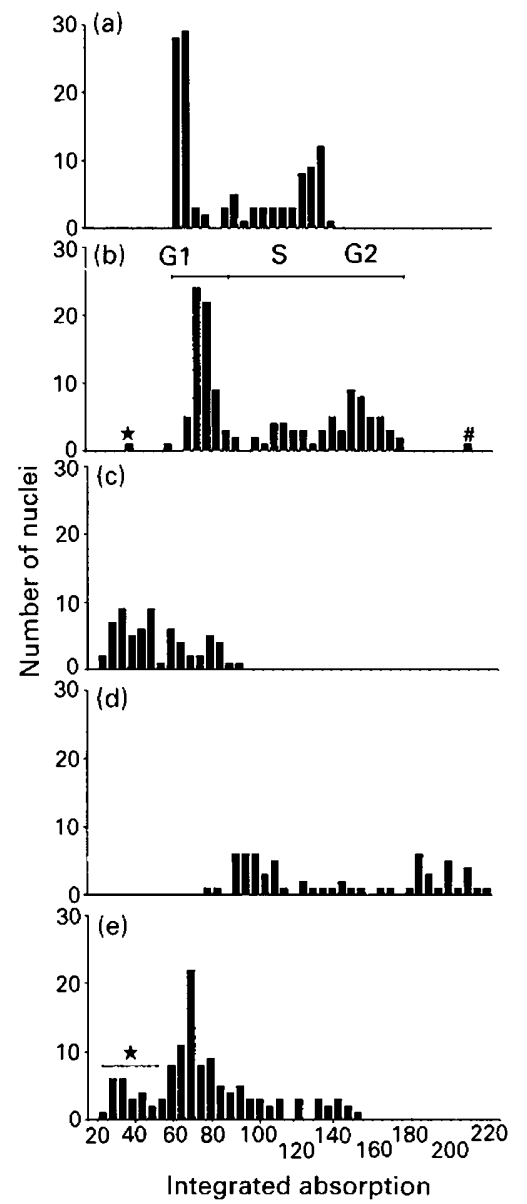

Fig. 1. Frequency distribution diagrams of the DNA values of the individual nuclei of: (a) actively dividing calf kidney fibroblasts, (b) an embryo that had been qualified as good, (c) a haploid embryo that had been qualified as good, (d) a triploid embryo that had been qualified as fair and (e) an embryo with hypodiploid nuclei that had been qualified as good. The DNA content is expressed as the integrated absorption (in arbitrary units). $\star$ : hypodiploid nuclei. $\$$ : hyperdiploid nuclei.

DNA value that was lower than the 'minimum G1 value' were considered as hypodiploid, whereas nuclei with a DNA content that was higher than $5 \mathrm{C}$ were considered as hyperdiploid. Nuclei designated as hypodiploid occasionally included haploid nuclei, and nuclei designated as hyperdiploid occasionally included polyploid nuclei.

The integrated absorbance of a G1 phase nucleus is about 80 arbitrary absorbance units (Fig. Ib). As bovine cells normally contain 60 chromosomes, it can be assumed that the amount of DNA of one chromosome in the GI phase is represented by 1.3 arbitrary absorbance units. This is only a rough approximation, as bovine chromosomes vary in size (see for an example a bovine karyotype, King and Linares, 1983).

\section{Results}

\section{Total haploidy and total triploidy}

In general, normal diploid DNA values varied slightly among embryos $( \pm 10 \%$ deviation from the DNA values of the 

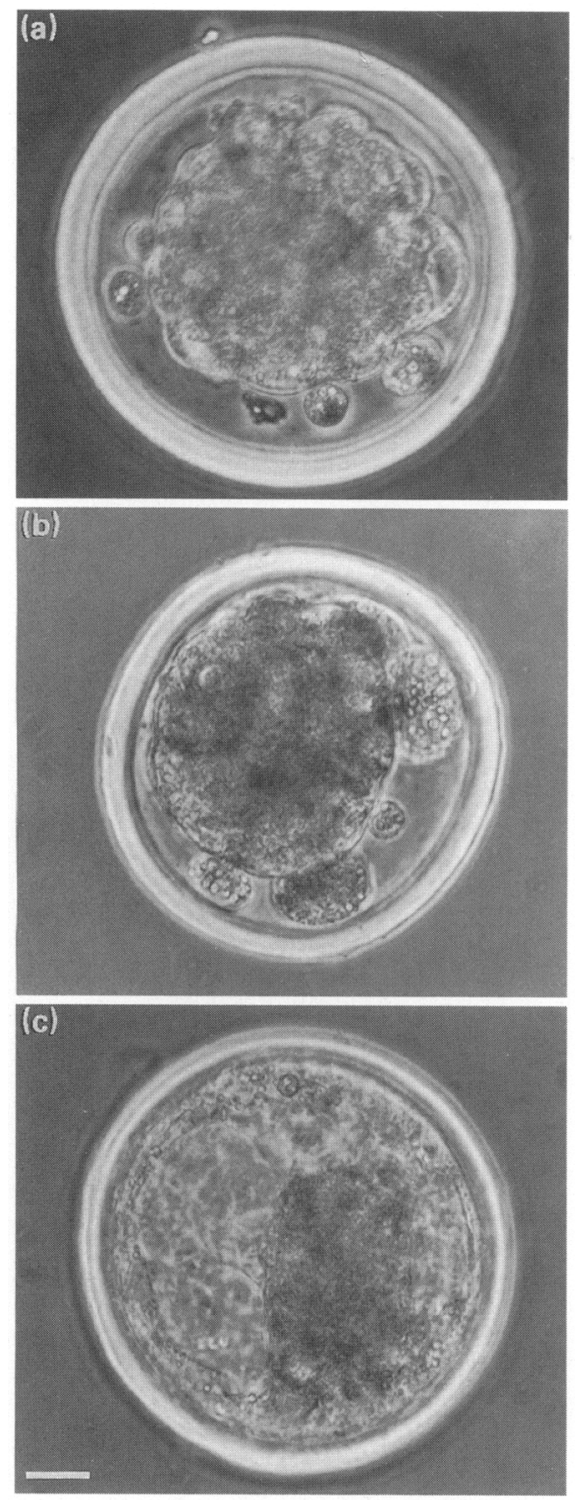

Fig. 2. Photographs of: (a) the haploid embryo (compare Fig. 1c), (b) the triploid embryo (compare Fig. Id) after collection, (c) the triploid embryo after a culture for $24 \mathrm{~h}$. Bar represents $25 \mu \mathrm{m}$.

fibroblasts (Fig. 1a)). However, completely abnormal DNA values were found in two of the 52 embryos studied (3.8\%). One embryo was completely haploid (Fig. Ic), whereas the other embryo was completely triploid (Fig. 1d). No metaphase spreads were present in the preparation of the haploid embryo. The triploidy of the other embryo was confirmed by the number of chromosomes in six metaphase spreads, which was about 84 (the normal chromosome number in cows is $2 n=60$ ).

The haploid embryo had been graded as a good compact morula (Fig. 2a), and the triploid embryo as a fair compact morula (Fig. 2b). The triploid embryo had been cultured for $24 \mathrm{~h}$, and developed during this period into a morphologically normal blastocyst (Fig. 2c). After fixation, the haploid embryo had 90 nuclei of which $6(6.7 \%)$ were degenerated, while the triploid embryo had 59 nuclei of which three $(5.1 \%)$ were degenerated.

\section{Mixoploidy}

Hyperdiploid nuclei. Hyperdiploid nuclei, with amounts of DNA in the range of $5 \mathrm{C}-9 \mathrm{C}$, were regularly observed in the otherwise diploid embryos. They were found in various numbers in nine of the 27 'non-cultured' diploid embryos (33.3\%) (Table 1). No hyperdiploid nuclei were found in the group of excellent embryos, whereas such nuclei were observed in seven of the $15(46.7 \%)$ good embryos, in one of the six (16.7\%) fair embryos and in one of the three $(33.3 \%)$ poor embryos. In the group of good embryos, the percentage of hyperdiploid nuclei varied between 1.1 and 7.5 . The percentages of hyperdiploid nuclei in the fair and in the poor embryo were 5.0 and 6.3 , respectively.

Four of the embryos with hyperdiploid nuclei came from the same donor cow. The mean percentage ( \pm SEM) of hyperdiploid nuclei in these embryos was $5.6 \pm 1.0$. This percentage is high compared with the mean percentage of hyperdiploid nuclei in the remaining five embryos, which was $2.5 \pm 0.8$.

Hypodiploid nuclei. Nearly all (25) of the 27 embryos had hypodiploid nuclei. Because haploid polar bodies can still be present in morulae and blastocysts (to a maximum of three), only embryos with more than three hypodiploid nuclei can be designated as abnormal. Fourteen of the 27 (51.9\%) embryos were therefore considered to contain hypodiploid nuclei (Table $\mathrm{I}$; for a representative example of an embryo with hypodiploid nuclei see Fig. 1e). More than three hypodiploid nuclei were found in two of the three (66.7\%) excellent embryos, in seven of the $15(46.7 \%)$ good embryos, in four of the six $(66.7 \%)$ fair embryos and in one of the three $(33.3 \%)$ poor embryos. Percentages of these nuclei varied from 3.2 to 4.7 in the group of excellent embryos, from 5.0 to 23.2 in the group of good embryos, and from 7.9 to 48.1 in the group of fair embryos. The poor embryo had $8.0 \%$ hypodiploid nuclei. Five $(35.7 \%)$ of the embryos with more than three hypodiploid nuclei also had hypodiploid nuclei (Table 1).

\section{Culture of embryos}

An additional group of embryos was cultured for $24 \mathrm{~h}$. Of the 23 embryos that were analysed, three had been classified as excellent, 14 as good, and six as fair. No DNA measurement could be made of preparations from embryos that had been qualified as poor after collection.

The embryonic stage before culture varied from the morula stage to the early blastocyst stage. Of the group of excellent embryos, one was a compact morula and two were early blastocyst. Of the group of good embryos, two were morulae, four were compact morulae and eight were early blastocysts, and of the group of fair embryos one was a morula, two were compact morulae and three were early blastocysts. Most of the embryos (20) developed at least one stage further during culture. However, one early blastocyst that had been graded as good degenerated, while two early blastocysts that had been graded as fair became arrested during culture. 
Table 1. Morphological quality, embryonic stage, total number of nuclei, number of degenerated nuclei, number of normal and pycnotic hyperdiploid nuclei and hypodiploid nuclei of the individual bovine embryos that were fixed immediately after collection ('non-cultured' embryos)

\begin{tabular}{|c|c|c|c|c|c|c|c|c|c|}
\hline \multirow{2}{*}{$\begin{array}{l}\text { Morphological } \\
\text { quality }\end{array}$} & \multirow{2}{*}{$\begin{array}{l}\text { Embryonic } \\
\text { stage }\end{array}$} & \multirow{2}{*}{$\begin{array}{c}\text { Total } \\
\text { number of } \\
\text { nuclei }\end{array}$} & \multirow{2}{*}{$\begin{array}{l}\text { Degenerated } \\
\text { nuclei } \\
(\%)\end{array}$} & \multicolumn{3}{|c|}{ Hyperdiploid nuclei } & \multicolumn{3}{|c|}{ Hypodiploid nuclei } \\
\hline & & & & Normal & Pycnotic & $\%$ & Normal & Pycnotic & $\%$ \\
\hline \multirow{3}{*}{ Excellent } & $\mathrm{CM}$ & 127 & $6(4.7)$ & - & - & 0 & 1 & - & 0.8 \\
\hline & $\mathrm{CM}$ & 127 & $14(11.0)$ & - & - & 0 & 4 & 2 & 4.7 \\
\hline & $\mathrm{EB}$ & 127 & $3(2.4)$ & - & - & 0 & 4 & - & 3.2 \\
\hline \multirow[t]{15}{*}{ Good } & $\mathrm{CM}$ & 127 & $20(15.8)$ & - & - & 0 & - & 1 & 0.8 \\
\hline & $\mathrm{CM}$ & 141 & $14 \quad(9.9)$ & 2 & - & 1.4 & - & 2 & 1.4 \\
\hline & $C M$ & 86 & $0 \quad(0)$ & - & - & 0 & 2 & - & 2.3 \\
\hline & $\mathrm{CM}$ & 160 & $44(27.5)$ & - & - & 0 & 17 & 5 & 13.8 \\
\hline & $\mathrm{CM}$ & 99 & $14(14.1)$ & 2 & - & 2.0 & 18 & 5 & 23.2 \\
\hline & $\mathrm{CM}$ & 118 & $16(13.6)$ & - & - & 0 & - & 3 & 2.5 \\
\hline & $\mathrm{CM}$ & 90 & $2(2.2)$ & 1 & - & 1.1 & 3 & - & 3.3 \\
\hline & $\mathrm{CM}$ & 134 & $13(9.7)$ & 10 & - & 7.5 & - & 3 & 2.2 \\
\hline & $C M$ & 109 & $6 \quad(5.5)$ & 3 & - & 2.8 & 9 & - & 8.3 \\
\hline & $\mathrm{CM}$ & 140 & $14(10.0)$ & 5 & - & 3.6 & - & 7 & 5.0 \\
\hline & EB & 97 & $6 \quad(6.2)$ & - & - & 0 & - & 2 & 2.1 \\
\hline & $\mathrm{EB}$ & 118 & $12(10.2)$ & - & - & 0 & 10 & 1 & 9.3 \\
\hline & EB & 153 & $13(8.5)$ & - & - & 0 & 18 & 2 & 13.1 \\
\hline & EB & 109 & $3(2.8)$ & - & - & 0 & 2 & - & 1.8 \\
\hline & $\mathrm{EB}$ & 83 & $3(3.6)$ & 4 & - & 4.8 & 4 & 1 & 6.0 \\
\hline \multirow[t]{6}{*}{ Fair } & $\mathrm{CM}$ & 95 & $3(3.2)$ & - & - & 0 & - & - & 0 \\
\hline & $\mathrm{CM}$ & 114 & $5 \quad(4.4)$ & - & - & 0 & 9 & - & 7.9 \\
\hline & $\mathrm{CM}$ & 89 & $11(12.4)$ & - & - & 0 & 8 & - & 9.0 \\
\hline & $\mathrm{CM}$ & 106 & $9(8.5)$ & - & - & 0 & 50 & 1 & 48.1 \\
\hline & $\mathrm{CM}$ & 101 & $16(15.8)$ & - & - & 0 & 8 & 6 & 13.9 \\
\hline & $\mathrm{EB}$ & 100 & $23(23.0)$ & 4 & 1 & 5.0 & $\mathrm{I}$ & 2 & 3.0 \\
\hline \multirow[t]{3}{*}{ Poor } & $16-32 \mathrm{C}$ & 24 & $2(8.3)$ & - & - & 0 & - & - & 0 \\
\hline & M & 45 & $7(15.6)$ & - & - & 0 & 2 & 1 & 6.7 \\
\hline & $\mathrm{M}$ & 112 & $7 \quad(6.3)$ & 7 & - & 6.3 & - & 9 & 8.0 \\
\hline
\end{tabular}

16-32C: 16-32 cell stage, M: morula, CM: compact morula, EB: early blastocyst.

As no DNA measurements could be obtained from the 'cultured' embryos that had been graded as poor after collection, the results of the group of 'cultured' embryos were compared with the results of only those 'non-cultured' embryos that had been graded as excellent, good and fair.

The mean number of nuclei and the percentage of degenerated nuclei in the group of 'cultured embryos' was approximately the same as those in the corresponding group of 'non-cultured' embryos (Table 2). However, the percentage of hypodiploid nuclei was significantly lower in the group of 'cultured' embryos than in the corresponding group of 'noncultured' embryos. Although the percentage of hyperdiploid nuclei tended to be lower in the group of 'cultured' embryos than in the group of 'non-cultured' embryos, this difference was not significant.

\section{Discussion}

In the study reported here the $2 \mathrm{C}$ DNA values of the embryos showed a $10 \%$ variation compared with those of bovine fibro-
Table 2. Mean number of nuclei and mean percentages of degenerated, hypodiploid and hyperdiploid nuclei in 'noncultured' and 'cultured' bovine embryos that had been classified as excellent, good and fair

\begin{tabular}{lcc}
\hline Parameter & $\begin{array}{c}\text { Non-cultured } \\
\text { embryos }\end{array}$ & $\begin{array}{c}\text { Cultured } \\
\text { embryos }\end{array}$ \\
\hline $\begin{array}{c}\text { Number of embryos } \\
\text { Mean number of nuclei } \\
\begin{array}{c}\text { Mean percentage of } \\
\text { degenerated nuclei }\end{array}\end{array}$ & $114.6 \pm 4.4$ & $119.2 \pm 7.3$ \\
$\begin{array}{c}\text { Mean percentage of } \\
\text { hyperdiploid nuclei } \\
\text { Mean percentage of } \\
\text { hypodiploid nuclei }\end{array}$ & $9.4 \pm 1.4$ & $9.7 \pm 4.7$ \\
\hline
\end{tabular}

Values are means \pm SEM

*Significantly different $(P<0.02)$ from non-cultured embryos (Student's $t$ test). 
blasts. Apart from a normal biological variation, these differences are probably caused by the fact that each embryo was individually treated, as the frequency distribution of the DNA values of the embryos was not affected by higher or lower $2 \mathrm{C}$ values. Hence, chromosome abnormalities such as total haploidy and total triploidy could still be detected. Moreover, as a large number of nuclei per embryo could be analysed, these chromosomal abnormalities could be assessed unequivocally. This situation is in contrast to conventional cytogenetic methods, which depend upon the presence of dividing cells. In bovine embryos, there are usually few dividing cells.

Until now, total haploidy has not been reported in day-7 bovine embryos developed in vivo. However, in bovine embryos matured, fertilized and developed in vitro (Iwasaki $e t$ al., 1989) and in porcine (Van der Hoeven et al., 1985) and ovine (Murray et al., 1986b) embryos developed in vivo, a low incidence of total haploidy has also been observed. Conversely, in human (Angell et al., 1983) and murine (Whittingham, 1980; Kaufman, 1985; Surani et al., 1987) embryos, complete haploidy, which is thought to be the result of the parthenogenetic activation of the oocyte, occurs more frequently.

The low incidence of triploidy observed here is in agreement with the results of studies in rabbits (Fujimoto et al., 1974), sheep (Murray et al., 1986b), mice (Martin-Deleon and Boice, 1983), pigs (Long and Williams, 1980) and cows (Hare et al., 1980).

Both the haploid and triploid embryos did not differ in morphology from other diploid embryos of the same morphological quality and embryonic stage. This result has also been reported for in vitro fertilized and developed human triploid embryos (Dandekar et al., 1990).

The cytophotometric DNA measurements that were used in the study reported here were not sensitive enough to detect abnormalities such as monosomy and trisomy, as the amount of DNA per chromosome was relatively low. Furthermore, as the embryos were treated individually, the measured DNA values varied among embryos. However, this latter variation did not affect the within embryo evaluation, with regard to the ability to detect either individual hypodiploid or hyperdiploid nuclei in the otherwise diploid embryos.

In the present study, relatively high percentages of both hypodiploid and hyperdiploid nuclei were observed. These percentages may even have been underestimated, as the DNA values of part of the hyperdiploid nuclei in the GI phase and all of the hypodiploid nuclei in the G2 phase were within the range of values of normal diploid GI and G2 nuclei.

The observed incidence of hyperdiploid nuclei was, in general, higher than reported for mouse (Varmuza et al., 1988), pig (Moon et al., 1975; Van der Hoeven et al., 1985; Long and Williams, 1982), sheep (Murray et al., 1986a) and cow (Hare et al., 1980; King et al., 1987, 1988) embryos after chromosome analysis.

In contrast to the present study, hypodiploidy in embryos developed in vivo has been reported only with regard to either monosomy (Long and Williams, 1980; King and Linares, 1983; Murray et al., 1985, 1986a), or the presence of a few haploid cells in otherwise diploid embryos (King et al., 1979; King and Picard, 1985). However, in preparations of bovine embryos developed in vitro, hypodiploid metaphase spreads have been found more frequently (King et al., 1988; Iwasaki et al., 1989).
The presence of both hypodiploid and hyperdiploid nuclei in embryos suggests the frequent occurrence of mitotic segregation failures such as non-disjunction and anaphase lagging (King et al., 1988). As a result of these segregation failures, chromosomes are unequally distributed over the two daughter cells. In some cases, chromosomes can be lost during mitosis. These chromosomes can be incorporated into separate micronuclei (Molls et al., 1982; Saito et al., 1984a, b; Pampfer et al., 1989). In the present study, micronuclei were occasionally observed. However, because they were very small, they could not be measured. Alternatively, it is also possible that segregation failures can lead to the formation of multinuclear cells, containing several nucleus-like pseudonuclei as described by Tesarik et al. (1987). These pseudonuclei are larger than micronuclei and are probably hypodiploid. Next to segregation failures leading to hyper- and hypodiploid nuclei, polyploid nuclei can be formed as a consequence of the absolute failure of chromosome segregation during mitosis, which is similar to the process of endomitosis (Sarto et al., 1982; King, 1990).

The high incidences of hyper- and hypodiploid nuclei that are observed in the current study may have resulted from the fact that the embryos were collected from excised uteri of slaughtered donor cows (De Leeuw, 1992). However, it is probably the result of the fact that nearly all of the nuclei of an embryo could be analysed, whereas the identification of polyploid and hypodiploid/haploid cells in other studies could only be determined in dividing cells that were in the metaphase of the cell cycle. It is also possible that most of the hypodiploid nuclei that were observed in the present study could not have been detected with the use of conventional cytogenetic methods. Hypodiploid nuclei lack chromosomes, and they may, therefore, lack vital genes. The cells that contain hypodiploid nuclei that lack these vital genes may stop dividing and eventually degenerate. This contention is supported by two observations in the group of 'cultured' embryos. First, the percentage of hypodiploid nuclei, but not that of hyperdiploid nuclei, was lower in the group of 'cultured' embryos than in the group of 'non-cultured' embryos. Second, although most of the 'cultured' embryos had developed during culture, their mean number of nuclei was not significantly greater than the mean number of nuclei in the group of 'non-cultured' embryos.

In general, the presence of hyperdiploid nuclei has been regarded as a normal developmental characteristic (Barlow and Sherman, 1972; Copp, 1978; Hare et al., 1980; Rossant and Tamura-Lis, 1981; Surani and Barton, 1984). In previous studies, it has been suggested that the occurrence of polyploidy may be associated with culture conditions (Barlow and Sherman, 1972; Johnson and Rossant, 1981). This was not observed in the present study, although it is possible that culture conditions may have selected embryos with few abnormal nuclei, as most of the embryos that were analysed had developed during culture. A measurable preparation could be obtained from only one of the embryos that degenerated during culture. The number of nuclei in this embryo was low (45, of which 16 were degenerated; data not shown), and no hypo- or hyperdiploid nuclei were found in this embryo.

In two other studies (King et al., 1987, 1988), it was suggested that the occurrence of polyploid nuclei may be associated with the poor quality of the embryos. The results of the present study, on the contrary, show that neither the Downloaded from Bioscientifica.com at 04/26/2023 01:07:58PM 
presence of hypodiploid nuclei nor of hyperdiploid nuclei in the embryos was associated with their morphology. However, the results do suggest a possible relationship between the donor cow and the incidence of hyperdiploid nuclei (Hare et al., 1980), as four embryos with a relatively high percentage of hyperdiploid nuclei were all derived from the same donor cow.

It is concluded that the relatively high incidence of hyperdiploid and hypodiploid nuclei may indicate the frequent occurrence of chromosomal segregation failures during mitosis in bovine embryos. These failures may cause the death of cells, and hence may contribute to preimplantation losses.

It is not possible to select for embryos that are mixoploid or even totally haploid or triploid by examining their morphology alone. Furthermore, the presence of hypodiploid nuclei in the blastomeres of the otherwise diploid embryos may have consequences when determining the sex or genetic disorders in biopsies of single blastomeres using DNA amplification techniques (Kirszenbaum et al., 1990).

The authors would like to thank S. J. Dieleman and M. M. Bevers (Department of Herd Health and Reproduction, Faculty of Veterinary Medicine, University of Utrecht) for determination of hormone concentrations in the donor cows, the members of the staff of the Department of Cytochemistry and Cytometry (Sylvius Laboratories Faculty of Medicine, University of Leiden, The Netherlands) for their hospitality and A. A. Bosma (Department of Cell Biology and Histology, Faculty of Veterinary Medicine, University of Utrecht) for critical reading of the manuscript. This work was, in part, supported by a grant of the Royal Dutch Cattle Syndicate.

\section{References}

Angell RR, Aitken RJ, Van Look PFA, Lumsden MA and Templeton AA (1983) Chromosome abnormalities in human embryos after in vitro fertilization Nature 303 336-338

Barlow PW and Sherman MI (1972) The biochemistry of differentiation of mouse trophoblast: studies on polyploidy Journal of Embryology and Experimental Morphology 27 2, 447-465

Barlow P, Owen DAJ and Graham C (1972) DNA synthesis in the preimplantation mouse embryo Joumal of Embryology and Experimental Morphology 27 $431-445$

Bolton VN, Oades PJ and Johnson MH (1984) The relationship between cleavage, DNA replication, and gene expression in the mouse 2-cell embryo Journal of Embryology and Experimental Morphology 79 139-163

Chrisholm JC (1988) Analysis of the fifth cell cycle of mouse development Journal of Reproduction and Fertility 84 29-36

Copp AJ (1978) Interaction between inner cell mass and trophectoderm of the mouse blastocyst. I. A study of cellular proliferation Journal of Embryology and Experimental Morphology 48 109-128

Dandekar PV, Martin MC and Glass RH (1990) Polypronuclear embryos after in vitro fertilization Fertility and Sterility $53510-514$

De Leeuw AM (1992) Number and viability of embryos coilected in vivo or from the excised uteri of slaughtered donor cows Theriogenology 37 907-913

Dieleman SJ and Bevers MM (1987) Effects of monoclonal antibody against PMSG administered shortly after the preovulatory LH surge on time and number of ovulations in PMSG/PG-treated cows Journal of Reproduction and Fertility 81 553-562

Duijndam WAL and Van Duijn P (1973) The dependence of the absorbance of the final chromophore formed in the Feulgen-Schiff reaction of the $\mathrm{pH}$ of the medium Histochemie 35 373-375

Duijndam WAL and Van Duijn P (1975) The influence of chromatin compactness on the stoichiometry of the Feulgen-Schiff procedure studied in model films. II. Investigations on films containing condensed or swollen chicken erythrocyte nuclei Journal of Histochemistry and Cytochemistry 23 891-900

Duijndam WAL, Smeulders AWM, Van Duijn P and Verweij AC (1980a) Optical errors in scanning stage absorbance cytophotometry. I. Procedures for correcting apparent integrated absorbance values for distributional, glare, and diffraction errors Joumal of Histochemistry and Cyfochemistry 28 388-394

Duijndam WAL, Van Duijn P and Riddersma SH (1980b) Optical errors in scanning stage absorbance cytophotometry. II. Application of correction factors for residual distributional error, glare, and diffraction error in practical cytophotometry Joumal of Histochemistry and Cytochemistry 28 $395-400$

Dyban AP (1983) An improved method for chromosome preparations from preimplantation mammalian embryos, oocytes or isolated blastomeres Stain Technology 58 2, 69-72

Fischer B and Schumacher A (1991) Embryonic development and incidence of aneuploidy in two rabbit strains of different fecundity Journal of Reproduction and Fertility $9241-46$

Fujimoto S, Pahlavan N and Dukelow WR (1974) Chromosome abnormalities in rabbit preimplantation blastocysts by superovulation Journal of Reproduction and Fertility 40 177-181

Graumann W (1953) Zur Standardisierung des Schiffschen Reagens Zeitschrift für Wissenschaftlichen Mikroskopie 61 225-226

Greve T and Del Campo M (1986) Embryo loss following embryo transfer in cattle and swine. In Embryonic Mortality in Farm Animals pp 179-194 Eds JM Sreenan and MG Diskin. Martinus Nijhoff Publishers, Dordrecht

Hare WCD, Singh EL, Betteridge KJ, Eaglesome MD, Randall GCB, Mitchell D and Bilton RJ (1980) Chromosomal analysis of 159 bovine embryos collected 12 to 18 days after estrus Canadian Journal of Genetics and Cytology 22 $615-626$

Iwasaki S, Shioya Y, Masuda H, Hanada A and Nakahara T (1989) Incidence of chromosomal abnormalities in early bovine embryos derived from in vitro fertilization Gamete Research 22 83-91

Johnson MH and Rossant J (1981) Molecular studies on cells of the trophectodermal lineage of the postimplantation mouse embryo joumal of Embryology and Experimental Morphology 61 103-116

Kastelic JP, Northey DL and Ginther OJ (1991) Spontaneous death on days 20 to 40 in heifers Theriogenology 35 351-363

Kaufman MH (1985) An hypothesis regarding the origin of aneuploidy in man: indirect evidence from an experimental model journal of Medical Genetics 22 171-178

King WA (1990) Chromosome abnormalities and pregnancy failure in domestic animals. In Advances in Veterinary Science and Comparative Medicine Vol. 34 Domestic Animal Cytogenetics pp 229-250 Ed RA McFeely. Academic Press, San Diego

King WA and Linares T (1983) A cytogenetic study of repeat-breeder heifers and their embryos Canadian Veterinary Journal 24 112-115

King WA and Picard L (1985) Haploidy in preattachment bovine embryos Canadian Journal of Genetics and Cytology 27 69-73

King WA, Linares T, Gustavsson I and Bane A (1979) A method for preparation of chromosomes from bovine zygotes and blastocysts Veterinary Science Communications 3 51-56

King WA, Guay P and Picard L (1987) A cytogenetical study of 7-day-old bovine embryos of poor quality Genome 29 160-164

King WA, Sirard MA and First NL (1988) The chromosomal complement of morulae produced by in vitro fertilization of in vitro matured bovine embryos Proceedings of the 11th International Congress on Animal Reproduction and Artificial Insemination Dublin Abstract 335

Kirszenbaum M, Cotinot C, Leonard M, Vaiman M and Fellous M (1990) Diagnostic du sexe des embryons bovins par biologie moleculaire Reproduction, Nutrition, Developpement (Supplement 1) 125s-132s

Lindner GM and Wright RW, Ir (1983) Bovine embryo morphology and evaluation Theriogenology 20 407-417

Long SE and Williams CV (1980) Frequency of chromosomal abnormalities in early embryos of the domestic sheep (Ovis aries) Joumal of Reproduction and Fertility 58 197-201

Long SE and Williams CV (1982) A comparison of the chromosome complement of inner cell mass and trophoblast cells in Day-10 pig embryos Journat of Reproduction and Fertility 66 645-648

Mares V and Van der Ploeg M (1980) Cytophotometric re-investigation of the DNA content in Purkinje cells of the rat cerebellum Histochemistry 69 161-167

Martin-Deleon PA and Boice ML (1983) Spontaneous heteroploidy in one-cell mouse embryos Cytogenetics and Cell Genetics 35 57-63

Molls M, Streffer C, Van Beuningen D and Zamboglou N (1982) X irradiation in $\mathrm{G} 2$ phase of two-cell mouse embryos in vitro: cleavage, blastulation, cell kinetics, and fetal development Radiation Research 91 235-242 
Moon RG, Rashad MN and Mi MP (1975) An example of polyploidy in pig blastocysts Journal of Reproduction and Fertility 45 147-149

Murray JD, Moran C, Boland MP, Doff AM and Nancarrow CD (1985) Cytogenetic analysis of 34 early stage bovine embryos from superovulated Hereford donors Canadian Journal of Genetics and Cytology 27 483-486

Murray JD, Moran C, Boland MP, Nancarrow CD, Sutton R, Hoskinson RM and Scaramuzzi RJ (1986a) Polyploid cells in blastocysts and early fetuses from Australian Merino sheep Journal of Reproduction and Fertility 78 439-446

Murray JD, Boland MP and Moran C (1986b) Frequency of chromosomal abnormalities in embryos from superovulated Merino ewes Journal of Reproduction and Fertility 78 433-437

O'Rand MG, Herman B, Diguiseppi J, Halme J, Hammond MG and Talbert LM (1986) Analysis of deoxyribonucleic acid distribution in noncleaving oocytes from patients undergoing in vitro fertilization Fertility and Sterility 46 452-460

Pampfer S, Streffer C and Muller WU (1989) Micronucleus formation in 2-cell embryos after in vitro $X$-irradiation of mouse spermatozoa Mutation Research 210 191-196

Rossant J and Tamura-Lis W (1981) Effect of culture conditions on diploid to giant-cell transformation in post-implantation mouse trophoblast Journal of Embryology and Experimental Morphology 62 217-227

Rottman OJ (1981) Chromosome preparations from single blastomeres after colchemid treatment and removal from rabbit morulae unsuitable for sexing in routine embryo transfer Theriogenology 15 321-326

Saito H, Berger T, Mishell DR, Jr and Mars RP (1984a) Effect of variable concentration of serum on mouse embryo development Fertility and Sterility $\mathbf{4 1}$ $460-464$

Saito H, Berger T, Mishell DR, Jr and Mars RP (1984b) The effect of serum fractions on embryo growth Fertility and Sterility 41 761-765
Sarto GE, Stubblefield PA and Therman E (1982) Endomitosis in human trophoblast Human Genetics 62 228-232

Singh EL and Hare WCD (1980) The feasibility of sexing bovine morula stage embryos prior to embryo transfer Theriogenology 14 421-427

Sreenan JM and Diskin MG (1986) The extent and timing of embryonic mortality in cattle. In Embryonic Mortality in Farm Animals pp 1-11 Eds JM Sreenan and MG Diskin. Martinus Nijhoff Publishers, Dordrecht

Surani MAH and Barton SC (1984) Spatial distribution of blastomeres is dependent on cell division order and interactions in mouse morulae Developmental Biology 102 335-343

Surani MAH, Barton SC and Norris ML (1987) Experimental reconstruction of mouse eggs and embryos: an analysis of mammalian development Biology of Reproduction 36 1-16

Tesarik J, Kopeckny V, Plachot M and Mandelbaum J (1987) Ultrastructural and autoradiographic observations on multinucleated blastomeres of human cleaving embryos obtained by in vitro fertilization Human Reproduction 2 127-136

Van der Hoeven FA, Cuijpers MP and De Boer P (1985) Karyotypes of 3- or 4day old pig embryos after short in-vitro culture Joumal of Reproduction and Fertility 75 593-597

Van der Ploeg M, Van den Broek K, Smeulders AWM, Vossepoel AM and Van Duijn P (1977) HIDACSYS: computer programs for interactive scanning cytophotometry Histochemistry 54 273-288

Varmuza S, Prideaux V, Kothary R and Rossant J (1988) Polytene chromosomes in mouse trophoblastic giant cells Development 102 127-134

Whittingham DG (1971) Survival of mouse embryos after freezing and thawing Nature 223 125-126

Whittingham DG (1980) Parthenogenesis in mammals Oxford Reviews of Reproductive Biology 2 205-231 